\title{
Evaluation of the Performance of ENACTS MAP-ROOM Products over Tanzania
}

\author{
Philbert M. Luhunga ${ }^{1}$, Emanuel T. Kidebwana ${ }^{2}$, Agnes L. Kijazi ${ }^{1}$, Ladislaus Chang'a ${ }^{1}$, \\ Hashim Ng'ongolo ${ }^{3}$, Alfred Kondowe ${ }^{4}$
}

\author{
${ }^{1}$ Research Section, Tanzania Meteorological Authority, Dar es Salaam, Tanzania \\ ${ }^{2}$ Information and Communication Technology (ICT) Section, Tanzania Meteorological Authority, Dar es Salaam, Tanzania \\ ${ }^{3}$ Climatology and Climate Change Section, Tanzania Meteorological Authority, Dar es Salaam, Tanzania \\ ${ }^{4}$ Numerical Weather Prediction Section, Tanzania Meteorological Authority, Dar es Salaam, Tanzania \\ Email: *philbert.luhunga@meteo.go.tz
}

How to cite this paper: Luhunga, P.M., Kidebwana, E.T., Kijazi, A.L., Chang'a, L., Ng'ongolo, H. and Kondowe, A. (2019) Evaluation of the Performance of ENACTS MAP-ROOM Products over Tanzania. Atmospheric and Climate Sciences, 9, 202-212. https://doi.org/10.4236/acs.2019.92014

Received: December 13, 2018

Accepted: March 10, 2019

Published: March 13, 2019

Copyright (C) 2019 by author(s) and Scientific Research Publishing Inc. This work is licensed under the Creative Commons Attribution International License (CC BY 4.0).

http://creativecommons.org/licenses/by/4.0/ Open Access

\begin{abstract}
Tanzania has inadequate weather stations (28-synoptic weather stations), which are sparsely distributed over complex topographic terrain. Many places, especially rural areas, have no stations to monitor weather and climate. In this study, we evaluate the performance of ENACT-MAPROOM products over Tanzania with the aim of assessing their potential to supplement observed weather and climate data, especially over areas where there is limited number of weather stations. Monthly rainfall total and monthly averaged minimum and maximum temperatures from ENACT-MAPROOM are evaluated against observed data from 23 weather stations. The evaluation is limited to analyze how well the ENACT-MAPROOM products reproduce climatological trends, annual cycles and inter-annual variability of rainfall, minimum and maximum temperatures. Statistical analysis recommended by the World Meteorological Organization (WMO) that includes that correlation and trend analysis are used. It is found that ENACT-MAPROOM products reproduce the climatological trends, annual cycles and inter-annual variability of rainfall, minimum and maximum temperatures over most stations. The statistical relationship between ENACT-MAPROOM products against observed data from 23 weather stations using Pearson correlation coefficient indicates that ENACT-MAPROOM products bear strong and statistically significant correlation coefficient to observed data. The overall evaluation here finds high skills of ENACT-MAPROOM products in representing rainfall and temperature over Tanzania, suggesting their potential use in planning and decision making especially over areas with limited number of weather stations.
\end{abstract}

\section{Keywords}

Climate Change, Rainfall, Temperature, ENACT-MAPROOM Products 


\section{Introduction}

Climate change and variability depends on long-term observational climate datasets [1]. These datasets, especially in developing countries are observed by ground based weather stations. However, the number of ground based weather stations in developing countries are not adequate to provide climate dataset at high temporal and spatial resolution [2] [3]. For instance, Tanzania has few weather stations (28-synoptic weather stations) which are sparsely distributed over complex topographical terrain [4]. Many places, especially in rural areas where farming practices are predominant, have no weather stations to monitor climate change and variability. In order to overcome some of the challenges of data from ground based weather stations (large data gaps, sparse stations networks), satellite based gridded climate data are generated at high temporal and spatial resolutions.

The gridded climate data are now available at high temporal and spatial resolutions [5]. These include the Global Precipitation Climatology Project (GPCP at $1^{\circ}$ by $1^{\circ}$ spatial resolution), Tropical Rainfall Measuring Mission (TRMM, at $0.25^{\circ}$ by $0.25^{\circ}$ spatial resolution) and the Famine Early Warning System (FEW at $0.1^{\circ}$ by $0.1^{\circ}$ spatial resolution) [6]. However, the quality of gridded climate datasets depends on the number of ground weather observations used in merging and interpolation processes [7]. In developing countries, climate data are regarded as proprietary and not freely shared. This makes few numbers of weather stations that participate in the generation of global merged or interpolated climate products, and make them of inadequate quality to support adaptation decision in developing countries.

The Tanzania Meteorological Agency (TMA) has been working with the International Research Institute for Climate and Society (IRI) through Enhancing National Climate Services (ENACTS) initiative to produce country specific gridded climate data library (ENACTS MAPROOM). These merged climate datasets use all observed climate records available in the country and are designed to bring climate knowledge into national decision making by improving availability, access to, and use of climate information [8].

The climate datasets produced by IRI through ENACTS initiative are readily available and can be accessed by different stakeholders such as planners and decision makers. However, before providing knowledge and information to promote the use of ENACTS-MAPROOM products to different stakeholders for day to day and longer term planning, it is important to evaluate their performance to reproduce historical climate over different stations. In this study, the performance of MAPROOM product to reproduce present climate condition over different regions of Tanzania is evaluated.

\section{Data and Methodology}

\subsection{Study Area}

Tanzania is located in East African region between latitudes $1^{\circ} \mathrm{S}$ and $12^{\circ} \mathrm{S}$ and 
longitudes $29^{\circ} \mathrm{E}$ to $41^{\circ} \mathrm{E}$. The country possesses large area of $\left(945,000 \mathrm{~km}^{2}\right)$ rich in natural resources such as forest reserves, game reserves, Mount Kilimanjaro the highest peak in Africa, large water bodies such as Lake Victoria, Lake Tanganyika and Lake Nyasa the lowest peak in Africa. The climate over Tanzania is mainly controlled by the migration of the Inter-Tropical Convergence Zone (ITCZ) that migrates North and South with the overhead sun. This zone crosses the country when migrating southwards during October to February and Northwards in March, April and May. This movement makes areas over southern, Southwestern, Central and Western parts of the Country, to have single rainfall season that start in November and continue through April or May. Whilst areas over the North, northern coast, North-eastern Highlands, Lake Victoria basin and the Islands of Zanzibar (Unguja and Pemba) receive two distinct rainfalls seasons-the long rain season (Masika) that starts in March and continues through May (MAM) and the short rainfall season (Vuli) that starts in October and continues through December (OND). Seasonal rainfall over Tanzania usually ranges from 50 to $200 \mathrm{~mm}$ per month, with high regional variation and can be as much as $300 \mathrm{~mm}$ per month in wettest regions and seasons with possibility of occurrence of extreme events [4] [9] [10]. The annual average of rainfall and temperatures over Tanzania ranges from $534 \mathrm{~mm}$ to $1837 \mathrm{~mm}$ and $14.4^{\circ} \mathrm{C}$ to $26.4^{\circ} \mathrm{C}$ respectively.

\subsection{Data and Analysis}

Decadal total rainfall, and decadal mean of minimum and maximum temperatures for the period of 1983 to 2010 from 23 weather stations available from the CLIDATA archive at the Tanzania Meteorological Agency (TMA) were used to merge with decal total rainfall, and decadal mean of minimum and maximum temperatures for the period of 1983 to 2010 from satellite observations. The merged rainfall and temperatures are then interpolated across space and time into balanced panel of observations on fixed spatial scale or grid of $4 \mathrm{~km}$ by $4 \mathrm{~km}$ spatial resolution. Figures 1-3 respectively indicate spatial distribution of decadal total rainfall and minimum and maximum temperatures averaged over time from 1983 to 2010 . These merged and interpolated rainfall and temperature outputs are known as MAP-ROOM products.

The MAP-ROOM products gridded at $4 \mathrm{~km}$ by $4 \mathrm{~km}$ spatial resolutions were evaluated against actual measurement from weather stations using the interpolation method where the gridded MAP-ROOM products were interpolated to the location of weather station and the results were compared with observed station data. There are different interpolation techniques, the simplest is the nearest neighbor interpolation method that assume climate or weather variable at a given weather station is equal to that at the closest grid point [11] [12]. In this study nearest neighbor interpolation technique is used to interpolate MAP-ROOM products to the location of weather stations.

There are several criteria to evaluate the performance of MAP-ROOM products to represent observed weather or climate data [13]. However, there is no 


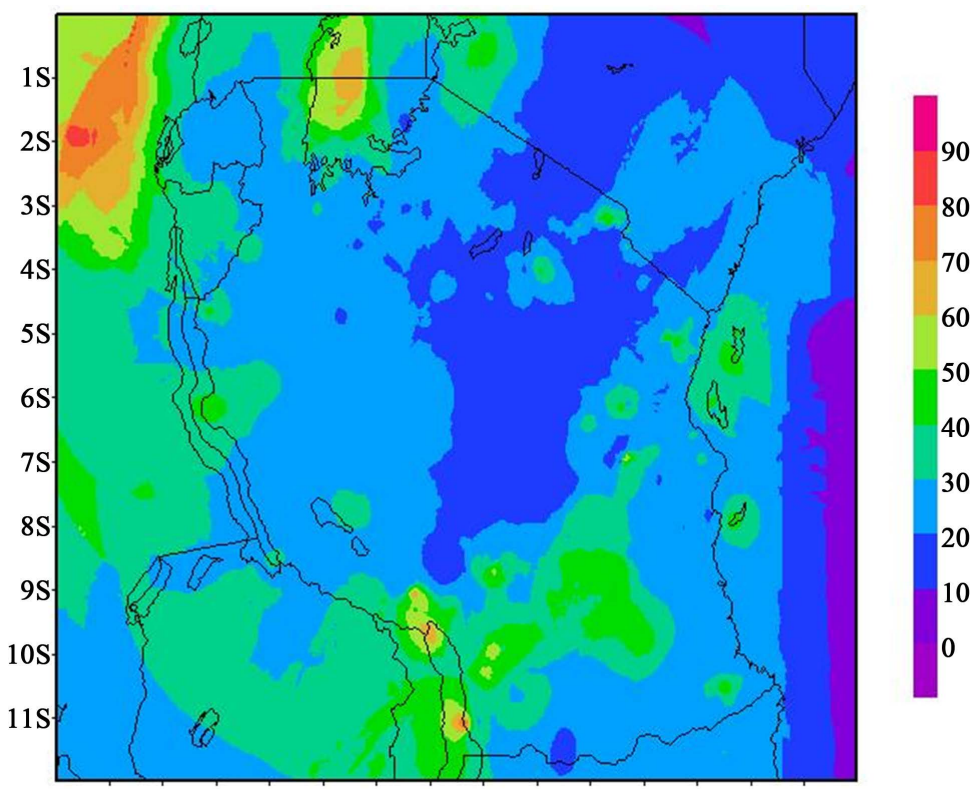

28E 29E 30E 31E 32E 33E 34E 35E 36E 37E 38E 39E 40E 41E

Figure 1. Spatial distribution of decadal rainfall in $(\mathrm{mm})$ over Tanzania averaged from (1983-2010).

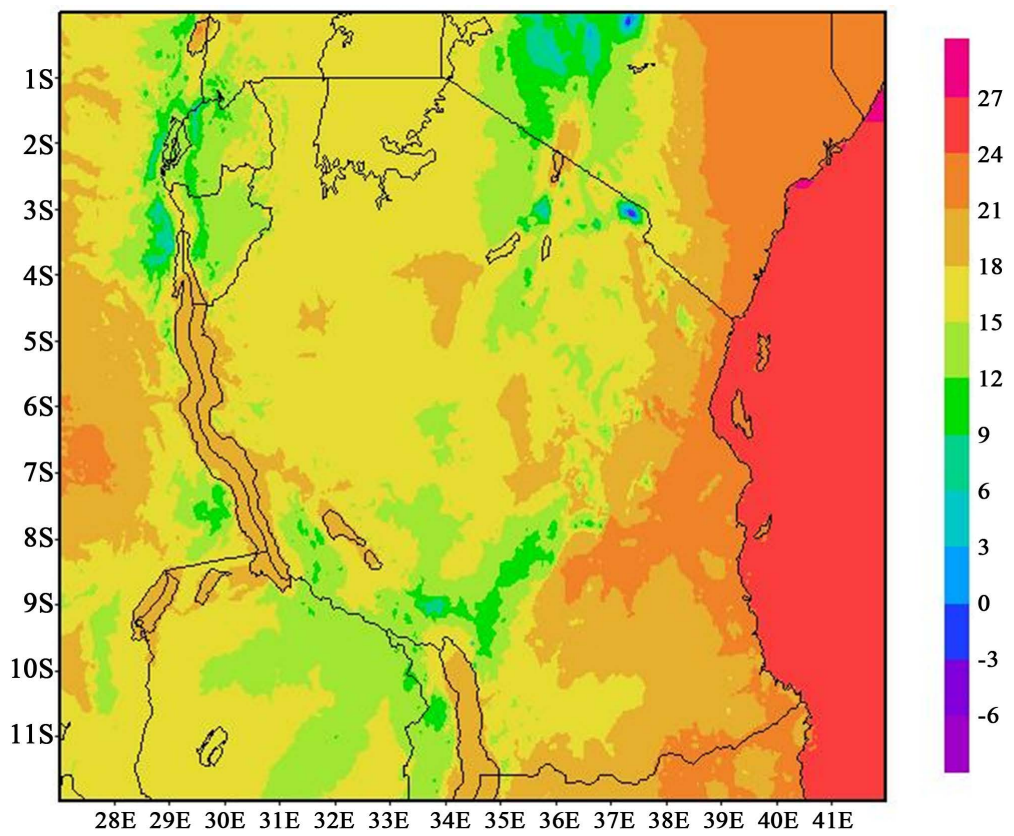

Figure 2. Spatial distribution of decadal minimum temperature in $\left({ }^{\circ} \mathrm{C}\right)$ over Tanzania averaged from (1983-2010).

individual evaluation technique or performance is considered superior, rather, it is combination of many techniques or measures that provide comprehensive evaluation. In this study, MAP-ROOM products are evaluated against observation data using a statistical measure recommended by the World Meteorological Organization (WMO) as reported by [14]. This statistic is the Pearson correlation coefficient defined as: 


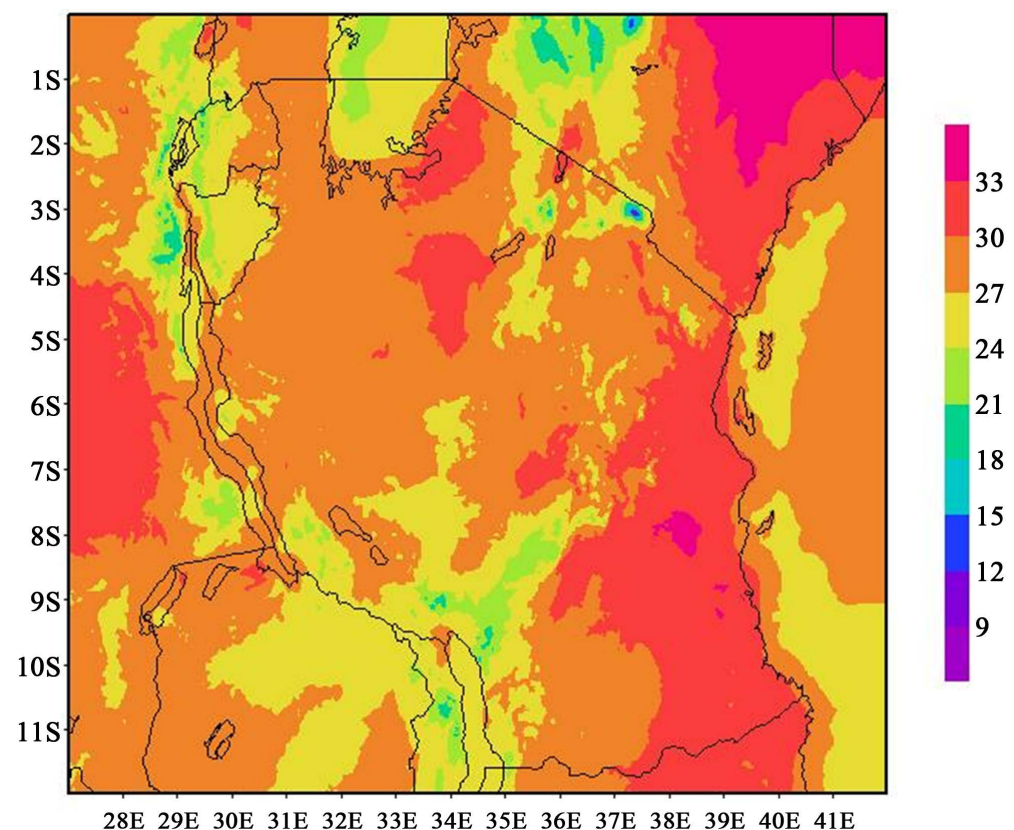

Figure 3. Spatial distribution of decadal maximum temperature in $\left({ }^{\circ} \mathrm{C}\right)$ over Tanzania averaged from (1983-2010).

$$
r_{(M P, O)}=\frac{\sum_{i=1}^{N}\left(M P_{i}-M P^{\prime}\right)\left(O_{i}-O^{\prime}\right)}{\sqrt{\sum_{i=1}^{N}\left(O_{i}-O^{\prime}\right)^{2}} \sqrt{\sum_{i=1}^{N}\left(M P_{i}-M P^{\prime}\right)^{2}}}
$$

where $M P$ and $O$ are the MAP-ROOM products and observed values respectively, while $i$ refers to the MAP-ROOM product and observed data pairs and $N$ is the total number of such pairs.

The ability of the MAP-ROOM products to reproduce the trend and the gradient of trend in inter-annual time series of rainfall, minimum and maximum temperatures are analyzed using the Mann-Kendall (MK) and Theil-SEN slope estimator methods [15] [16]. In this study all trends and gradient of trends are computed at station level for the period of 1983-2010. Table 1, lists geographical information of weather stations that are used in evaluation of MAP-ROOMS products.

\section{Results}

\section{Annual Cycle}

The performance of MAP-ROOM products to reproduce annual cycle of rainfall and temperature is presented in Figure 4. This figure was produced by averaging the values of observed rainfall total from 15 stations in the bimodal area Figure 4(a) and 8 stations in the unimodal area Figure 4(b), to get single representative time series for each rainfall pattern, that are compared with rainfall from MAP ROOM products (which are calculated in the same way) after interpolated to the location of weather stations. Minimum and maximum temperatures from 23 weather stations are averaged to get single time series minimum and maximum 


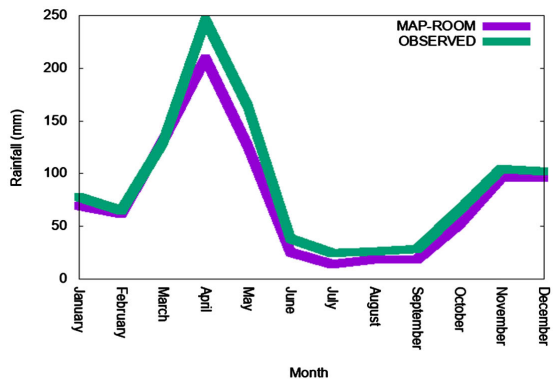

(a)

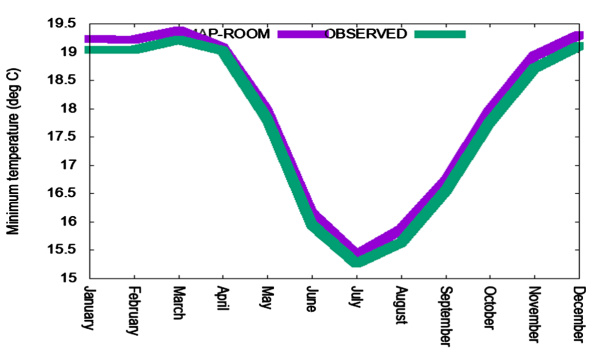

(c)

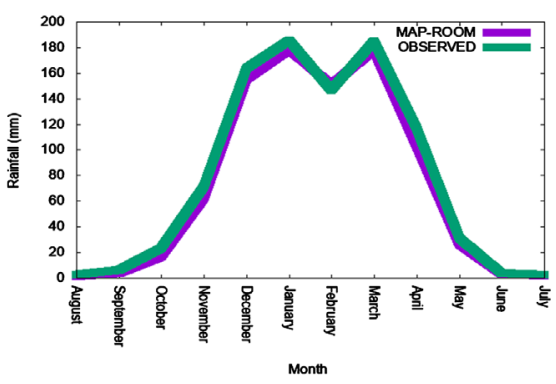

(b)

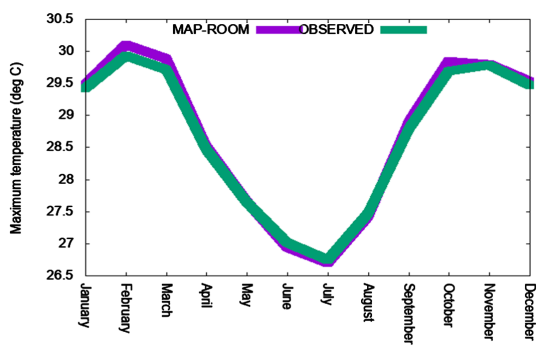

(d)

Figure 4. Annual cycles of bimodal (a) and unimodal (b) rainfall patterns (upper panel), and minimum (c) and maximum (d) temperatures (bottom panel) over Tanzania.

Table 1. Geographic information of weather stations managed by the Tanzania meteorological agency.

\begin{tabular}{ccccc}
\hline ID & Station Name & Latitude $\left({ }^{\circ} \mathrm{S}\right)$ & Longitude $\left({ }^{\circ} \mathrm{E}\right)$ & Alt $(\mathrm{m})$ \\
\hline 1 & Songea & 10.41 & 35.35 & 1067 \\
2 & Mtwara & 10.21 & 40.11 & 113 \\
3 & Bukoba & 1.2 & 31.49 & 1144 \\
4 & Musoma & 1.3 & 33.48 & 1147 \\
5 & Mwanza & 2.28 & 32.55 & 1140 \\
6 & Arusha & 3.2 & 36.37 & 1387 \\
7 & Moshi & 3.21 & 37.2 & 813 \\
8 & Kilimanjaro & 3.25 & 37.04 & 896 \\
9 & Kigoma & 4.53 & 29.4 & 820 \\
10 & Same & 0.5 & 37.43 & 860 \\
11 & Tabora & 5.05 & 32.5 & 1182 \\
12 & Tanga & 5.05 & 39.04 & 49 \\
13 & Dodoma & 6.1 & 35.46 & 1120 \\
14 & Ilonga & 6.46 & 37.02 & 503 \\
15 & Morogoro & 6.5 & 37.39 & 526 \\
16 & Kibaha & 6.5 & 38.38 & 167 \\
17 & Zanzibar & 6.13 & 39.13 & 18 \\
18 & Dar es Salaam & 6.53 & 39.12 & 53 \\
19 & Iringa & 7.4 & 35.45 & 1428 \\
20 & Mbeya & 8.56 & 33.28 & 1758 \\
21 & Mlingano & 8.09 & 38.54 & 2250 \\
22 & Igeri & 9.4 & 34.4 & 1344 \\
23 & Lyamungo & 3.23 & 37.25 & \\
\hline & & & & 183 \\
\hline
\end{tabular}


temperature to compare with MAP ROOM outputs (which are calculated in a similar way). It is found that outputs from MAP ROOM capture the timing and the magnitude of annual cycles of rainfall, minimum and maximum temperatures.

In the bimodal regions Figure 4(a) observed data exhibit two peaks of rainfall, a primary maximum in April and a secondary one in November and low minimum in June, July and August. This pattern is reproduced by MAP ROOM rainfall estimates, although they general overestimate rainfall from April to July. In the unimodal regions Figure 4(b) the length of rainfall season extends from September to June, having its peak in the month of January. MAP ROOM estimates systematically reproduce the timing and the magnitude of rainfall throughout the year in the unimodal regions.

The MAP ROOM products are assessed to reproduce the inter-annual variability of rainfall and temperature and the results are presented in Figure 5. This figure shows that MAP ROOM products captured the pattern of interannual variability in rainfall, minimum and maximum temperatures. However, minimum temperature estimates from MAP ROOM systematically underestimates the observed minimum temperature over Tanzania. Therefore, it can be concluded here that MAP ROOM products fairly capture the interannual variability of rainfall, minimum and maximum temperature.

The Pearson correlation coefficient is the measure of relationship between two variables. Here the correlation is performed to measure the strength of relationship between MAP ROOM products and observed data. Further statistical test is carried computing statistical significance level (p) and the coefficient of determination $\left(R^{2}\right)$. The significance test is important to understand how variable the results are and the value of $\mathrm{p}$ should be less than or equal to 0.05 for the results to be statistically significant.

Table 2 presents the Pearson correlation coefficient between annual cycles of MAP ROOM products and observed data from 23 weather stations. It is found that MAP ROOM products are strongly correlated with observed data over all weather stations in Tanzania. The bivariate regression to measure the explanation strength of MAP ROOM products on the variation of observed data over different weather station in Tanzania is presented in Table 2. This table indicates that MAP ROOM products explain better the variation of rainfall, minimum and maximum temperatures over all stations with the exception of Mlingano station where the coefficient of variation rainfall is weak $\left(\mathrm{R}^{2}=0.348, \mathrm{p}=\right.$ 0.04345). Table 3 indicates the Pearson correlation coefficient and the coefficient of determination between interannual variability of MAP ROOM products and observed data. It is clear that MAP ROOM products are statistically correlated with observed data in almost all stations. However, over Mlingano and Igeri MAP ROOM products are weakly correlated with observed data. This weak correlation may be attributed by the topography of the location of weather stations over Mlingano and Igeri which is generally surrounded by mountains. 


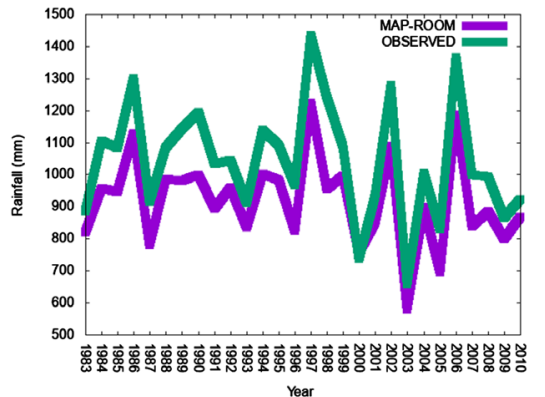

(a)

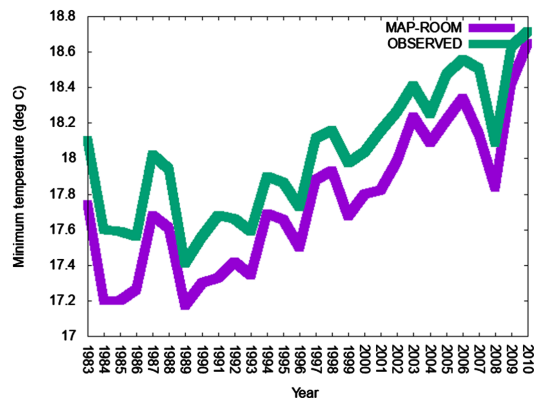

(c)

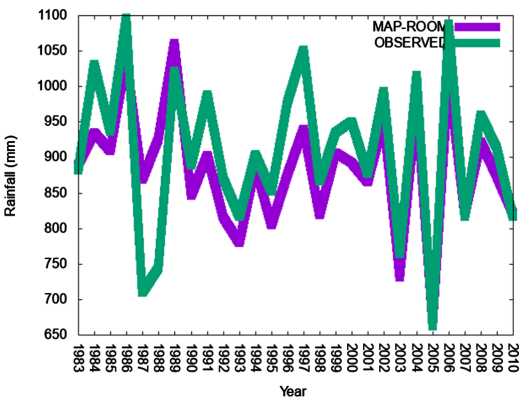

(b)

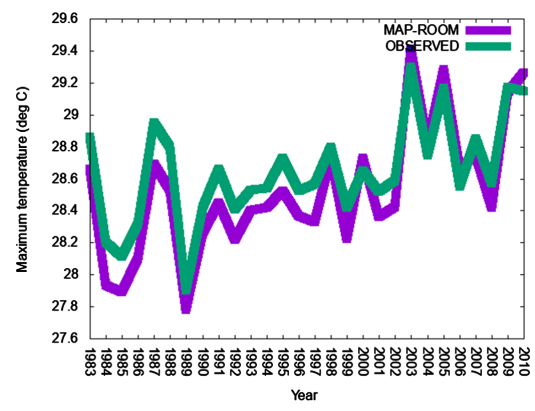

(d)

Figure 5. Interannual variability of bimodal (a) and unimodal (b) rainfall patterns (upper panel), and minimum (c) and maximum (d) temperatures (bottom panel) over Tanzania.

Table 2. Correlation coefficient and coefficient of determination between annual cycles of MAP-ROOM products and observed data.

\begin{tabular}{cccccccccc}
\hline \multirow{2}{*}{ Stations } & \multicolumn{3}{c}{ Rainfall } & \multicolumn{4}{c}{ Minimum temperature } & \multicolumn{3}{c}{ Maximum temperature } \\
\cline { 2 - 11 } & $\mathrm{R}$ & $\mathrm{R}^{2}$ & $\mathrm{p}$-values & $\mathrm{R}$ & $\mathrm{R}^{2}$ & $\mathrm{p}$-values & $\mathrm{R}$ & $\mathrm{R}^{2}$ & $\mathrm{p}$-values \\
\hline Arusha & 0.996 & 0.991 & $<0.0001$ & 0.996 & 0.991 & $<0.0001$ & 0.999 & 0.999 & $<0.0001$ \\
Bukoba & 0.999 & 0.998 & $<0.0001$ & 0.997 & 0.994 & $<0.0002$ & 0.996 & 0.992 & $<0.0001$ \\
Dia & 0.992 & 0.983 & $<0.0001$ & 0.999 & 0.998 & $<0.0003$ & 0.999 & 0.998 & $<0.0001$ \\
Morogoro & 0.983 & 0.967 & $<0.0001$ & 0.998 & 0.996 & $<0.0004$ & 0.998 & 0.997 & $<0.0001$ \\
Musoma & 0.996 & 0.993 & $<0.0001$ & 0.998 & 0.996 & $<0.0005$ & 0.973 & 0.946 & $<0.0001$ \\
Tanga & 0.994 & 0.987 & $<0.0001$ & 0.998 & 0.997 & $<0.0006$ & 0.999 & 0.997 & $<0.0001$ \\
Zanzibar & 0.995 & 0.990 & $<0.0001$ & 0.997 & 0.993 & $<0.0007$ & 0.999 & 0.998 & $<0.0001$ \\
Same & 0.987 & 0.974 & $<0.0001$ & 0.999 & 0.999 & $<0.0008$ & 0.999 & 0.997 & $<0.0001$ \\
Mwanza & 0.995 & 0.990 & $<0.0001$ & 0.999 & 0.998 & $<0.0009$ & 0.982 & 0.964 & $<0.0001$ \\
Moshi & 0.995 & 0.990 & $<0.0001$ & 0.996 & 0.992 & $<0.0010$ & 0.999 & 0.999 & $<0.0001$ \\
Ilonga & 0.993 & 0.986 & $<0.0001$ & 0.999 & 0.997 & $<0.0011$ & 0.999 & 0.998 & $<0.0001$ \\
Kibaha & 0.997 & 0.994 & $<0.0001$ & 0.995 & 0.989 & $<0.0012$ & 0.995 & 0.990 & $<0.0001$ \\
Kia & 0.982 & 0.964 & $<0.0001$ & 0.999 & 0.999 & $<0.0013$ & 0.990 & 0.999 & $<0.0001$ \\
Mlingano & 0.590 & 0.348 & 0.04345 & NIL & NIL & NIL & NIL & NIL & NIL \\
Dodoma & 0.993 & 0.986 & $<0.0001$ & 0.999 & 0.999 & $<0.0015$ & 0.998 & 0.996 & $<0.0001$ \\
Iringa & 0.996 & 0.991 & $<0.0001$ & 0.999 & 0.999 & $<0.0016$ & 0.998 & 0.996 & $<0.0001$ \\
Mbeya & 0.997 & 0.995 & $<0.0001$ & 0.999 & 0.999 & $<0.0017$ & 0.999 & 0.998 & $<0.0001$ \\
Mtwara & 0.988 & 0.976 & $<0.0001$ & 0.999 & 0.999 & $<0.0018$ & 0.997 & 0.994 & $<0.0001$ \\
Kigoma & 0.988 & 0.976 & $<0.0001$ & 0.962 & 0.925 & $<0.0019$ & 0.989 & 0.979 & $<0.0001$ \\
Songea & 0.997 & 0.994 & $<0.0001$ & 0.999 & 0.999 & $<0.0020$ & 0.990 & 0.979 & $<0.0001$ \\
Tabora & 0.993 & 0.986 & $<0.0001$ & 0.999 & 0.998 & $<0.0021$ & 0.978 & 0.956 & $<0.0001$ \\
Igeri & 0.997 & 0.994 & $<0.0001$ & NIL & NIL & NIL & NIL & NIL & NIL \\
Lyam & 0.685 & 0.469 & 0.013971 & 0.912 & 0.831 & $<0.0023$ & 0.942 & 0.887 & $<0.0001$ \\
\hline
\end{tabular}


Table 3. Correlation coefficient and coefficient of determination between inter-annual variability of MAP-ROOM products and observed data.

\begin{tabular}{|c|c|c|c|c|c|c|c|c|c|}
\hline \multirow{2}{*}{ Stations } & \multicolumn{3}{|c|}{ Rainfall } & \multicolumn{3}{|c|}{ Minimum temperature } & \multicolumn{3}{|c|}{ Maximum temperature } \\
\hline & $\mathrm{R}$ & $\mathrm{R} 2$ & p-values & $\mathrm{R}$ & $\mathrm{R}^{2}$ & $\mathrm{p}$-values & $\mathrm{R}$ & $\mathrm{R}^{2}$ & p-values \\
\hline Arusha & 0.888 & 0.789 & $<0.0001$ & 0.970 & 0.941 & $<0.0001$ & 0.949 & 0.900 & $<0.0001$ \\
\hline Bukoba & 0.720 & 0.519 & $<0.0001$ & 0.983 & 0.966 & $<0.0001$ & 0.824 & 0.678 & $<0.0001$ \\
\hline Dia & 0.960 & 0.921 & $<0.0001$ & 0.992 & 0.984 & $<0.0001$ & 0.995 & 0.990 & $<0.0001$ \\
\hline Morogoro & 0.936 & 0.877 & $<0.0001$ & 0.800 & 0.640 & $<0.0001$ & 0.798 & 0.637 & $<0.0001$ \\
\hline Musoma & 0.941 & 0.886 & $<0.0001$ & 0.959 & 0.920 & $<0.0001$ & 0.953 & 0.908 & $<0.0001$ \\
\hline Tanga & 0.960 & 0.922 & $<0.0001$ & 0.995 & 0.991 & $<0.0001$ & 0.837 & 0.700 & $<0.0001$ \\
\hline Zanzibar & 0.810 & 0.656 & $<0.0001$ & 0.965 & 0.930 & $<0.0001$ & 0.954 & 0.909 & $<0.0001$ \\
\hline Same & 0.954 & 0.911 & $<0.0001$ & 0.984 & 0.967 & $<0.0001$ & 0.942 & 0.887 & 0.150504 \\
\hline Mwanza & 0.957 & 0.916 & $<0.0001$ & 0.918 & 0.843 & $<0.0001$ & -0.279 & 0.078 & $<0.0001$ \\
\hline Moshi & 0.901 & 0.812 & $<0.0001$ & 0.995 & 0.990 & $<0.0001$ & 0.973 & 0.947 & $<0.0001$ \\
\hline Ilonga & 0.868 & 0.753 & $<0.0001$ & 0.933 & 0.870 & $<0.0001$ & 0.966 & 0.932 & $<0.0001$ \\
\hline Kibaha & 0.947 & 0.896 & $<0.0001$ & 0.913 & 0.833 & $<0.0001$ & 0.852 & 0.726 & $<0.0001$ \\
\hline Kia & 0.969 & 0.940 & $<0.0001$ & 0.981 & 0.963 & $<0.0001$ & 0.986 & 0.972 & $<0.0001$ \\
\hline Mlingano & 0.434 & 0.188 & 0.021074 & NIL & NIL & NIL & NIL & NIL & NIL \\
\hline Dodoma & 0.861 & 0.741 & $<0.0001$ & 0.971 & 0.942 & $<0.0001$ & 0.868 & 0.753 & $<0.0001$ \\
\hline Iringa & 0.927 & 0.859 & $<0.0001$ & 0.998 & 0.996 & $<0.0001$ & 0.923 & 0.852 & $<0.0001$ \\
\hline Mbeya & 0.963 & 0.928 & $<0.0001$ & 0.891 & 0.795 & $<0.0001$ & 0.838 & 0.702 & $<0.0001$ \\
\hline Mtwara & 0.953 & 0.908 & $<0.0001$ & 0.516 & 0.266 & 0.005 & 0.963 & 0.927 & $<0.0001$ \\
\hline Kigoma & 0.755 & 0.570 & $<0.0001$ & 0.496 & 0.246 & 0.007 & 0.553 & 0.306 & 0.002284 \\
\hline Songea & 0.944 & 0.891 & $<0.0001$ & 0.854 & 0.730 & $<0.0001$ & 0.577 & 0.333 & 0.001302 \\
\hline Tabora & 0.918 & 0.842 & $<0.0001$ & 0.752 & 0.565 & $<0.0001$ & 0.986 & 0.972 & $<0.0001$ \\
\hline Igeri & 0.070 & 0.005 & 0.721926 & NIL & NIL & NIL & NIL & NIL & NIL \\
\hline Lyam & 0.603 & 0.363 & 0.000691 & 0.571431 & 0.326533 & 0.001492 & 0.811 & 0.658 & $<0.0001$ \\
\hline
\end{tabular}

\section{Discussion}

In this study we presented the first attempt to evaluate the performance of MAP ROOM to reproduce observed climate data over different stations in Tanzania. The outputs from this evaluation are expected to encourage different stakeholders especially from rural areas where there is no weather stations to use MAP ROOM product in the planning and decision making. The evaluation focused on assessing the correlation coefficient and the coefficient of determination between MAP ROOM products and observed data from 23 weather station sparsely distributed over complex topographical terrain. Furthermore, the MAP ROOM products are assessed their ability to reproduce the annual cycles and interannual variability of observed rainfall, and temperatures. It is found that MAP ROOM products have strong correlation with observed data in most stations. 
Moreover, the coefficient of determination indicates strong and statistically significant coefficients that imply that MAP ROOM product can be used to supplement observed data in areas where there are no weather stations.

\section{Conclusion}

The study evaluated the performance of MAP ROOM products to reproduce annual cycles and inter-annual time series. The key objective was to assess if the MAP ROOM products can supplement observation in areas with limited number of weather stations. It is found that MAP ROOM products represent the annual and interannual variation of rainfall, minimum and maximum temperature over most stations. The correlation analysis indicates strong and statistically significant correlation between annual and interannual variation of MAP ROOM products and observed data. Therefore, it can be concluded that MAP ROOM product can supplement observation in areas that have no weather stations. This evaluation is necessary to different sectors (agriculture, livestock, health, transportation and construction just to mention few) that require high resolution weather and climate data for planning purposes. Through this evaluation we encourage them to use MAP ROOM product in their planning. Moreover, MAP ROOM products can be utilized in impacts studies. Finally, we recommend the use of MAP ROOM product in various activities including the preparation of the statement of Tanzania climate, which is prepared annually by the Tanzania Meteorological Agency.

\section{Acknowledgements}

We acknowledge funding support from the Global Framework for Climate Service (GFCS) phase II through the World Meteorological Organization (WMO). We also thank the Tanzania Meteorological Agency for the provision of data used in this study. Special thanks go to colleagues from the Tanzania Meteorological Agency (TMA) for fruitful discussion and recommendations that helped to improve this article.

\section{Conflicts of Interest}

The authors declare no conflicts of interest regarding the publication of this paper.

\section{References}

[1] Luhunga, P.M, Mutayoba, E. and Ng'ongolo, H. (2014) Homogeneity of Monthly Mean Air Temperature of the United Republic of Tanzania with HOMER. Atmospheric and Climate Sciences, 4, 70-77.

[2] Zambrano-Bigiarini, M., Nauditt, A., Birkel, C., Verbist, K. and Ribbe, L. (2017) Temporal and Spatial Evaluation of Satellite-Based Rainfall Estimates across the Complex Topographical and Climatic Gradients of Chile. Hydrology and Earth System Sciences, 21, 1295-1320.

https://www.hydrol-earth-syst-sci.net/21/1295/2017/ 
https://doi.org/10.5194/hess-21-1295-2017

[3] Liu, Z. (2015) Evaluation of Precipitation Climatology Derived from TRMM Multi-Satellite Precipitation Analysis (TMPA) Monthly Product over Land with Two Gauged-Based Products. Climate, 3, 964-982. https://doi.org/10.3390/cli3040964

[4] Luhunga, P.M., Botai, J. and Kahimba, F. (2016) Evaluation of the Performance of CORDEX Regional Climate Models in Simulating Present Climate Conditions of Tanzania. Journal of Southern Hemisphere Earth Systems Science, 66, 33-55.

[5] Dembélé, M. and Zwart, S.J. (2016) Evaluation and Comparison of Satellite-Based Rainfall Products in Burkina Faso, West Africa. International Journal of Remote Sensing, 37, 3995-4014. https://doi.org/10.1080/01431161.2016.1207258

[6] Sun, Q., Miao, C., Duan, Q., Ashouri, H., Sorooshian, S. and Hsu, K.-L. (2018) A Review of Global Precipitation Data Sets: Data Sources, Estimation, and Inter-Comparisons. Reviews of Geophysics, 56, 79-107. https://doi.org/10.1002/2017RG000574

[7] Dell, M., Benjamin, J.F. and Benjamin, A.O. (2014) What Do We Learn from the Weather? The New Climate-Economy Literature. Journal of Economic Literature, 52, 740-798 https://doi.org/10.1257/jel.52.3.740

[8] Barnston, A.G. and Tippett, M.K. (2014) Climate Information, Outlooks, and Understanding-Where Does the IRI Stand? Earth Perspectives, 1, 20. http://www.earth-perspectives.com/content/1/1/20

[9] Kijazi, A.L. and Reason, C.J.C. (2009) Analysis of the 2006 Floods over Northern Tanzania. International Journal of Climatology, 29, 955-970. https://doi.org/10.1002/joc.1846

[10] Kijazi, A.L. and Reason, C.J.C. (2009) Analysis of the 1998-2005 Droughts over the North-Eastern Highlands of Tanzania. Climate Research, 38, 209-223. https://doi.org/10.3354/cr00784

[11] Hartkamp, A.D., De Beurs, K., Stein, A. and White, J.W. (1999) Interpolation Techniques for Climate Variables. NRG-GIS Series 99-01, MMYT, Mexico.

[12] Ly, S., Charles, C. and Degre, A. (2013) Geostatistical Interpolation of Daily Rainfall at Catchment Scale: The Use of Several Variogram Models in the Ourthe and Ambleve Catchments, Belgium. Hydrology and Earth System Sciences, 15, 2259-2274. https://www.hydrol-earth-syst-sci.net/15/2259/2011/ https://doi.org/10.5194/hess-15-2259-2011

[13] Flato, G., Marotzke, J., Abiodun, B., Braconnot, P., Chou, S.C., Collins, W., Cox, P., Driouech, F., Emori, S. , Eyring, V., Forest, C., Gleckler, P., Guilyardi, E., Jakob, C., Kattsov, V., Reason, C. and Rummukainen, M. (2013) Evaluation of Climate Models. In: Stocker, T.F., Qin, D., Plattner, G.-K., Tignor, M., Allen, S.K., Boschung, J., Nauels, A., Xia, Y., Bex, V. and Midgley, P.M., Eds., Climate Change 2013: The Physical Science Basis. Contribution of Working Group I to the Fifth Assessment Report of the Intergovernmental Panel on Climate Change, Cambridge University Press, Cambridge, New York, NY.

[14] Gordon, N. and Shaykewich, J. (2000) Guidelines on Performance Assessment of Public Weather Services. WMO/TD No. 1023, 32.

[15] Rodrigo, F.S. and Trigo, R.M. (2007) Trends in Daily Rainfall in the Iberian Peninsula from 1951 to 2002. International Journal of Climatology, 27, 513-529. https://doi.org/10.1002/joc.1409

[16] Ahmad, I., Tang, D., Wang, T.F., Wang, M. and Wagan, B. (2015) Precipitation Trends over Time Using Mann-Kendall and Spearman's rho Tests in Swat River Basin, Pakistan. Advances in Meteorology, 2015, Article ID: 431860. 